\title{
INFLUENCE OF CULTURE ON UNDERSTANDING ASTRONOMICAL CONCEPTS
}

\author{
Mazlan Othman \\ Physics Department, Universiti Kebangsaan Malaysia, \\ 43600 UKM, Bangi, Selangor D.E., Malaysia
}

\section{Introduction}

Culture is defined as a society's system of values, ideology and social codes of behavior; its productive technologies and modes of consumption; its religious dogmas, myths, and taboos; and its social structure, political system and decisionmaking process (Coombes, 1985). The cultural environment in which an individual is raised is thus fundamental to the life view with which he perceives his world. Since his world view encompasses ideas of space and time, it is therefore not surprising that his understanding of astronomical concepts is inextricably bound to his cultural envelope.

This paper sets out to examine some of the ways cultural complexities affect the understanding of astronomical concepts and thus to make the case for a more realistic approach to the teaching of astronomy in a multicultural society, recognizing the importance of culture and the way students learn (Burger, 1973; Teynolds and Skilbeck, 1976).

\section{Malaysia's Cultural Heritage}

Malaysia is a multiracial country with each group practicing its own culture and religion. The main groups are Malays, Chinese, and Indians, each of which has its own very rich and long established culture. Each of these cultures is, in turn, very different from the others (Ryan, 1971). These cultures also have interesting myths, dogmas, and taboos (see for example Knappert, 1980).

\section{The Study}

In order to see how cultural belief may affect the student's concepts, the introductory astronomy class at Universiti Kebangsaan Malaysia was given a Malay legend with which they were all familiar and was then required to answer some questions. The legend given is as follows.

The legend of the Owl and the Moon (Tan, 1984): A long time ago, the Moon fell in love with the Owl and married her. She went to live with him in the sky and they were very happy. Now, in those times the sky was very close to the Earth and there were seven suns instead of only one. One particularly hot day, a woman who was heavy with child came down from her house and she was striken 
by the heat so that she fell very ill. When her husband came back from the fields and saw what had happened, he was very angry. Taking his blowpipe and darts, he shot at the suns. One by one they fell, until finally there was only one sun left in the whole sky. The seventh sun, alarmed to see what became of his brothers, quickly soared up higher to escape a similar fate. In doing so, he pulled the sky up with him to the great height that it is today.

Now, while all this was happening, the Owl had been combing her hair and she accidentally dropped her gold comb. Spreading her wings, she immediately flew down to Earth to recover it, but alas, when she rose to fly back to the sky again, she found that it had moved up too high for her to reach. Poor Owl, how she wept!

She cried out to the Moon, "Oh, my husband! Take me back into the sky to be with you!"

But the Moon only looked down at her helplessly and replied, "Alas, I cannot, for the rift between us is too wide."

This is why, people say, the Owl comes out at night and looks longingly at the Moon, for she had been pining for her husband ever since.

The students were asked: How does the story teller perceive i) the moon ii) the sun iii) the sky? Does his perception agree with yours? Explain.

\section{The Results}

The results of the study are summarized in Table 1. As the number of Indian students in the group was not significant, only the Malay and Chinese responses have been tabulated.

Table 1. Results of Students' Response (\%).

\begin{tabular}{llcc}
\hline & & \multicolumn{2}{c}{ Cultural Group } \\
\cline { 3 - 4 } & & Chinese & Malay \\
\hline Living Moon: & Not Contradicting & 0 & 0 \\
& Contradicting & 100 & 100 \\
Multiple Suns: & Not Contradicting & 4 & 10 \\
& Contradicting & 96 & 90 \\
Sky: & Not Contradicting & 24 & 80 \\
& Contradicting & 76 & 20 \\
\hline
\end{tabular}

The results show that the perception of the moon as a living object by the story teller was in contradiction with all the students' own perceptions. A small number of students in each cultural group thought that it may have been possible that there were more than one sun in Earth's history. However, a dichotomy appears in each group's concept of the sky. Interviews of some of the students who had found no contradiction were subsequently carried out to ascertain the reasons for the trends. The interviews revealed that the Chinese students who had stated no contradiction 
in the concept of the sky actually had not understood the story. Of the Malays in this group, a small percentage did not understand what the perception of the story teller was, while slightly fewer than $20 \%$ thought that the sun carried the moon with it because of gravitational attraction. The majority thought that the sky was organized into layers and therefore, in order to preserve the layer structure, the moon had to move up accordingly with the sun, which was on the same layer as the moon.

This result came as a surprise because it did not seem to matter that they knew that the moon circles the Earth, that the Earth circles the sun, etc. When they were required to look at the sky from the Earth, in their minds they still arranged the celestial objects in layers. This finding is similar to that reported by Cole and Scribner (1974). They found in their study of perceptions of people from various cultures that formal education was not the principal determining factor. Informal instruction in the home was found to have played a much larger role. In the teaching of astronomy, this is a very important point to appreciate because unless the misconception about space is cleared up right at the beginning of the course, the students will not be able to follow some of the logical deductions they have to make from observations.

\section{Conclusion}

This study has shown that although the students are taught a lot of facts, how they subsequently structure and reconstruct these facts in their minds depend very much on some deep-rooted beliefs that may or may not be logical. In order to teach astronomy well, it appears that one must first break some cultural bonds.

\section{References}

Burger, H.G., 1973. "Cultural Pluralism and the School," in Brombeck, C.S, and Hill, W.H. (editors), Cultural Challenges to Education, Oxford University Press, London, pp. 5-22.

Cole, M. and Scribner, S., 1974. Culture and Thought, New York, John Wiley and Sons.

Coombes, P.H. 1985. The World Crisis in Education, New York, Oxford University Press, p. 244.

Knappert, J., 1980. Malay Myths and Legends, Kuala Lumpur, Heinemann Education Books (Asia) Ltd.

Reynolds, J. and Skilbeck, M., 1976, Culture and the Classroom, Open Books, London.

Ryan, N.J., 1971. The Cultural Heritage of Malaya, Kuala Lumpur, Longman (Malaysia).

Tan, Lillian, 1984. "Malaysian Tales in The Beginning," in Wings of Gold, Malaysian Airlines System Publication, pp 52-53. 


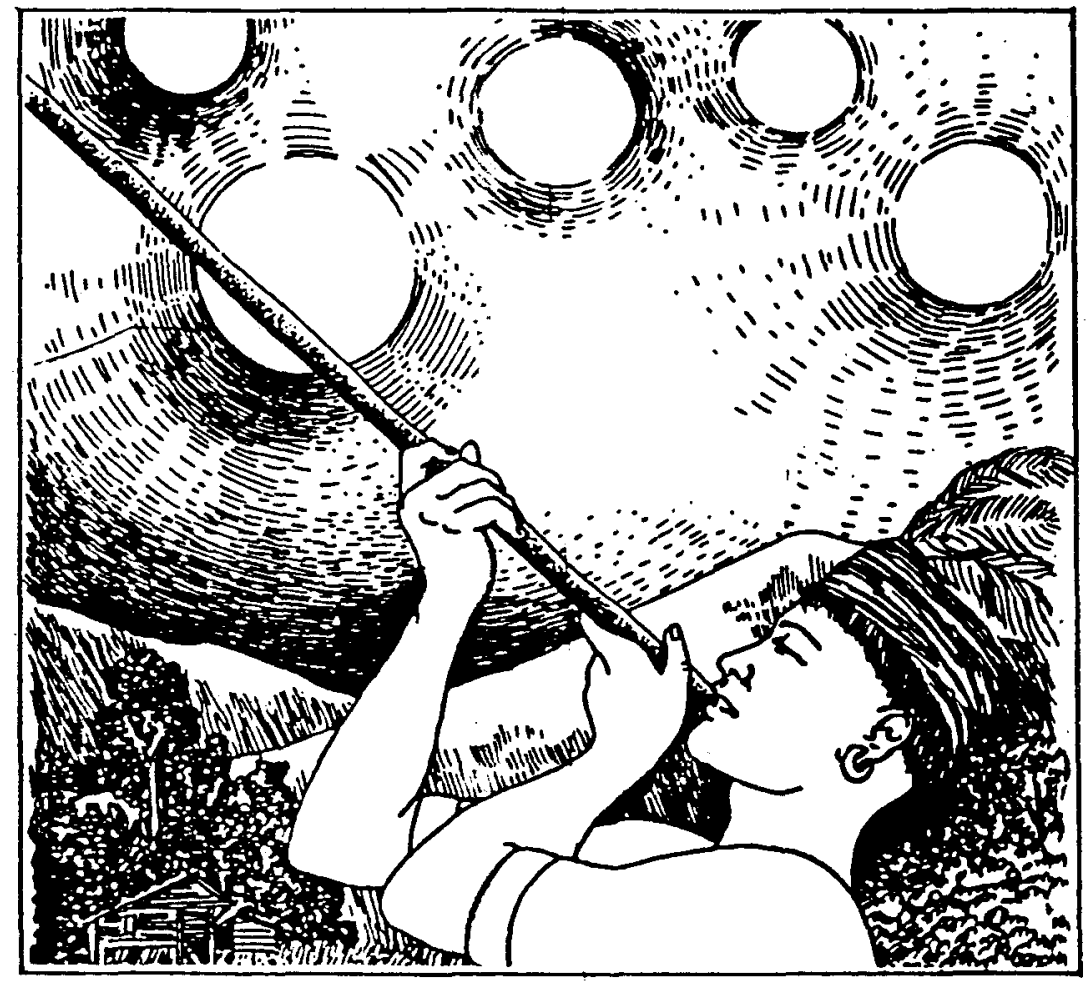

Taking his blow pipe and darts, he shot at the suns. (Extracted from Tan, 1984.)

\section{Discussion}

S. Torres-Peimbert: What is the level of the students and how large is the sample?

M. Othman: Students were from the Introductory Astronomy course given at the 2nd year level university and it's open to all students, science and non-science alike. Sample size was 102 students.

M. Zeilik: Your information and your comments yesterday point out a possible strategy for teaching introductory astronomy: the use of ethnoastronomy, the astronomy of a particular culture. This approach has the advantage of starting with the familiar astronomy, comparing other cultures, and focusing on naked-eye astronomy and students' misconceptions about the sky. P. Sadler and Project Star's interviews are ethnographic interviews revealing the ethnoastronomy of a particular subset of U.S. culture. 